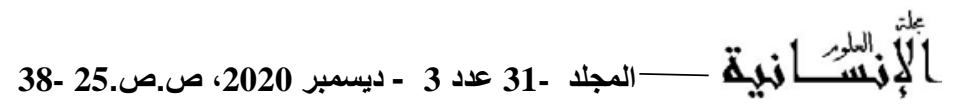

\title{
قراعة في تاريخ المسلسلات التلفزيونية الأمريكية
}

A reading in the history of American television series

تاريخ الاستلام : 2019/11/17؛ تاريخ القبول : 2020/09/06

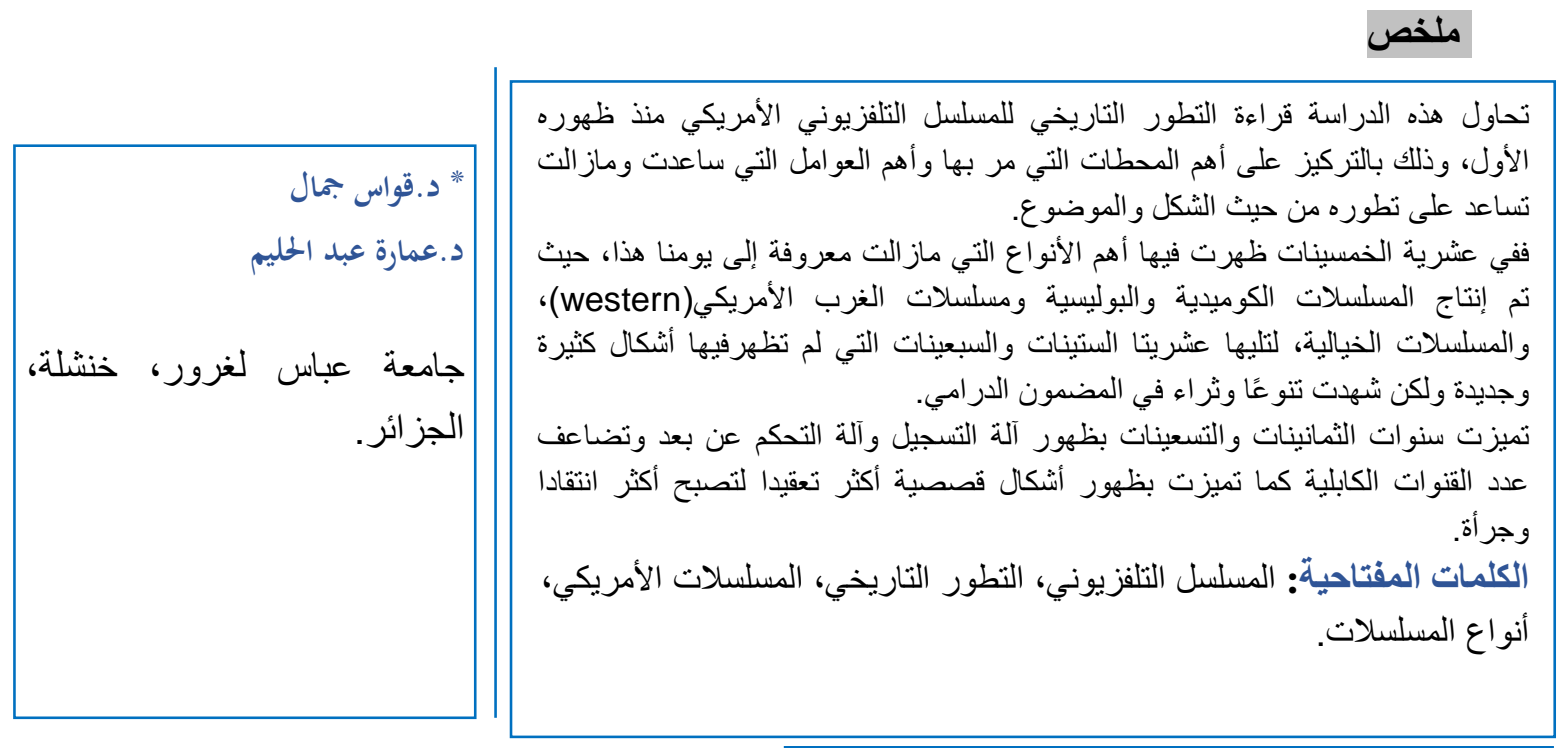

Abstract

This study attempts to read the historical development of the American television series since its beginning, by focusing on its import stages and the most important factors that contributed and still contribute to its development concerning content and form.

In 50s the most important kinds appeared which are still known nowadays. many series were produced such as comedy, policy, western and fiction.

This period is followed by the 60s and 70s when not really new form appeared but it witnessed variety and richness in the dramatic content.

The 80s and 90s were caracterised by the appearance of magnetoscope and remote control, the number of cable channels has grown considerably, dramatical kinds which are more complex also appeared.

Keywords: television series, the historical development, American soap operas, Types of series.

\section{Résumé}

Cette étude tente de lire l'évolution historique de la série télévisée américaine depuis ses débuts, en se concentrant sur ses étapes d'importation et les facteurs les plus importants qui ont contribué et contribuent encore à son développement concernant le contenu et la forme.

Dans les années 50 apparurent les espèces les plus importantes qui sont encore connues de nos jours. de nombreuses séries ont été produites telles que comédie, politique, western et fiction.

Cette période est suivie par les années 60 et 70 , alors que la forme n'était pas vraiment nouvelle mais qu'elle témoignait de la variété et de la richesse du contenu dramatique.

Les années 80 et 90 ont été caractérisées par l'apparition du magnétoscope et de la télécommande, le nombre de chaînes câblées a considérablement augmenté, des types dramatiques plus complexes sont également apparus

Mots clés: série télévisée, développement historique,Série américaine, Types de séries.

*Corresponding author, e-mail: halimitfc82@yahoo.com 


\section{I}

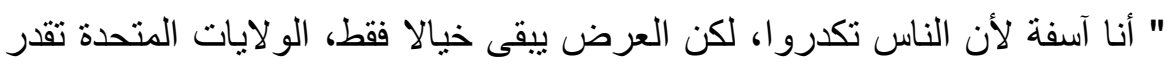

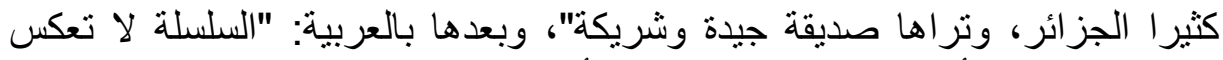

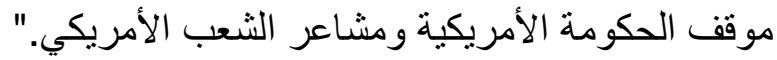

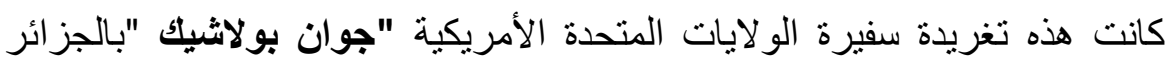

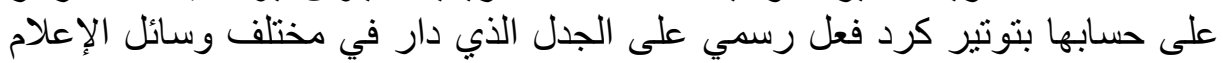

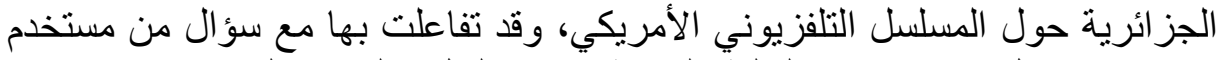

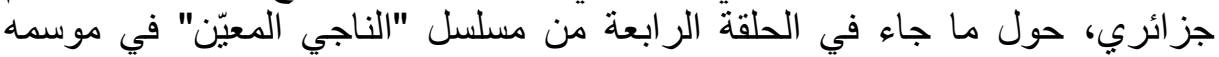

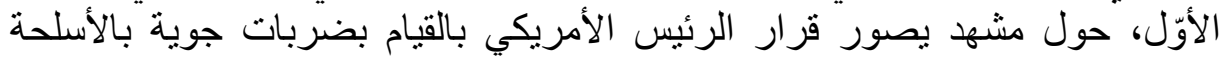

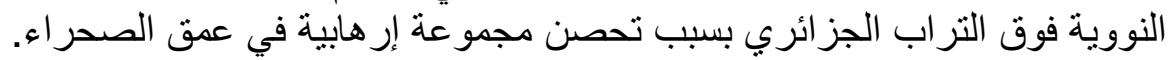

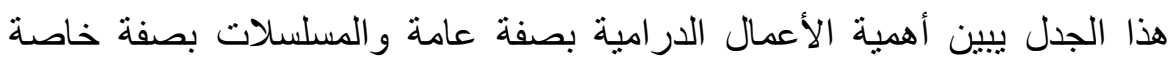

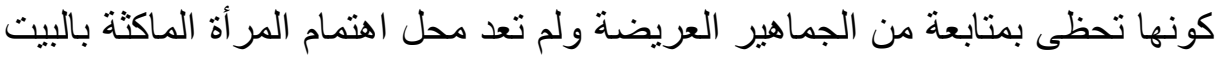

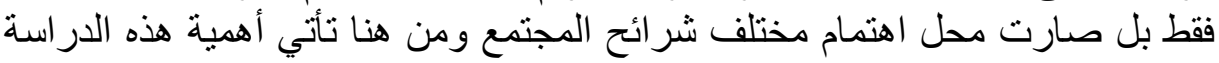

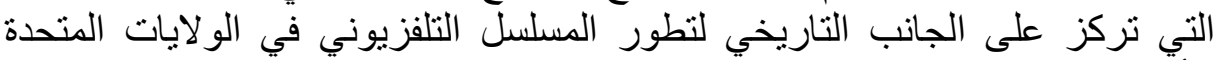

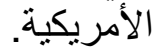

\section{الإطار المفاهيمي للاراسة}

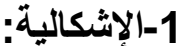

وُلدت المسلسلات التلفزيونية الأمريكية بميلاد التلفزيون ور افقت المجتمع الأمريكي

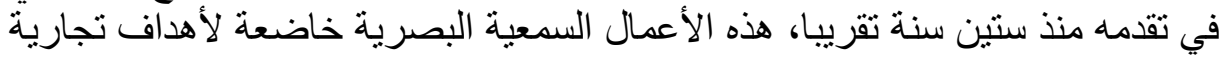

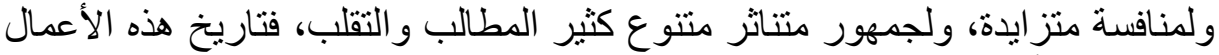

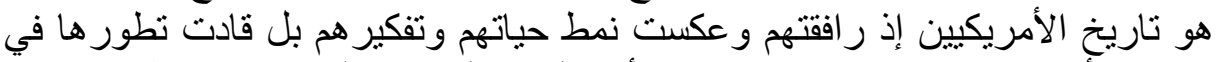

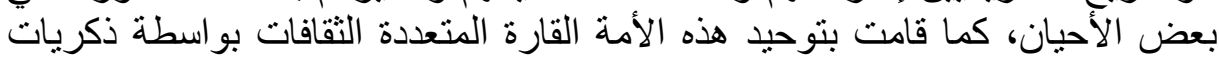

$$
\text { ومر اجع مشنركة. }
$$

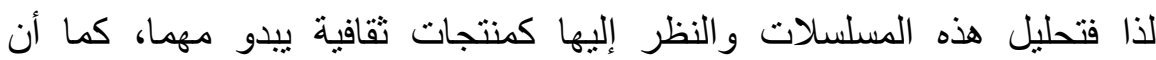

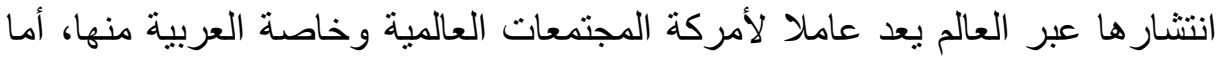

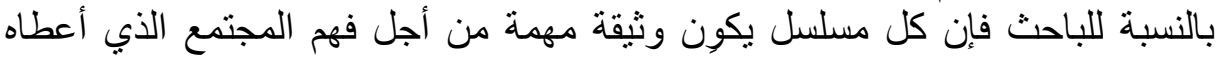

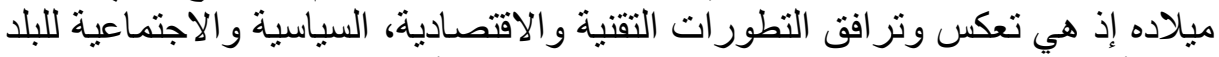
الذي أنتجها، ويسمح تحليلها بفهم تطور الذجنتمع الأمريكي وطريقة تفكيره خلال

الستين سنة الأخيرة.

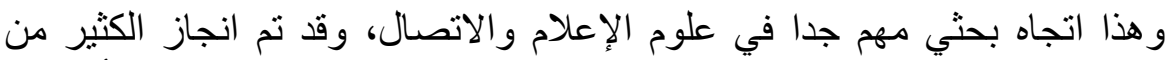

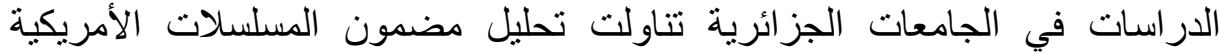

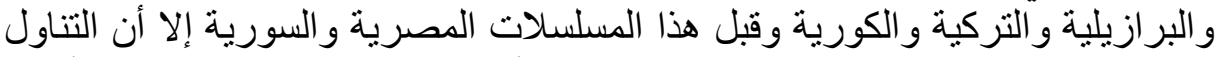

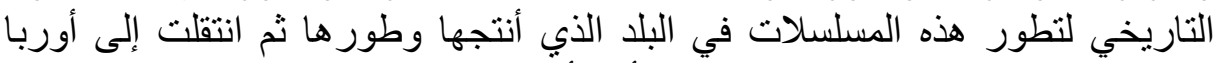

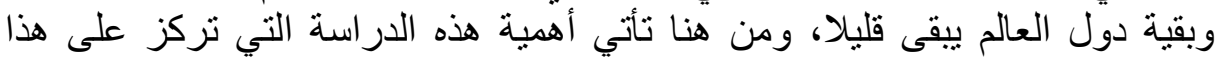

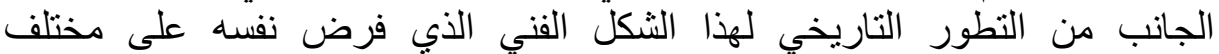

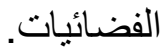

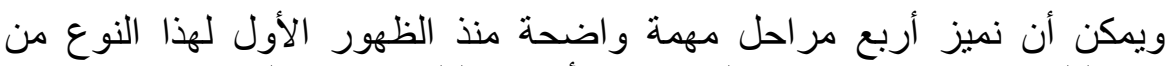

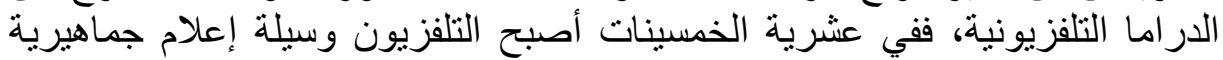

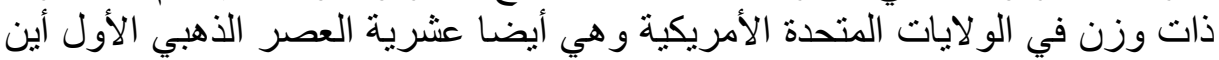

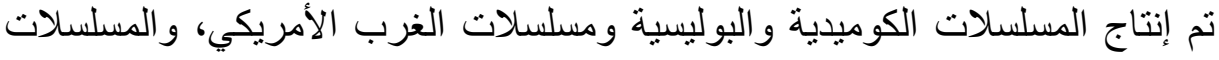




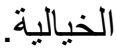

لتليها عشريتا الستينات و السبعينات اللتان تو افقان العصر الكلاسيكي حيث استقرت

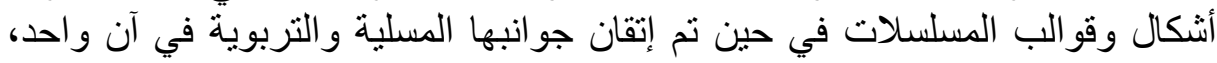

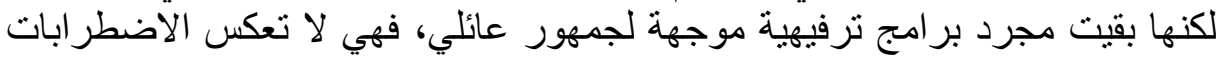
العميقة التي هزت المجتمع الأمريكي في تللك المرحلة.

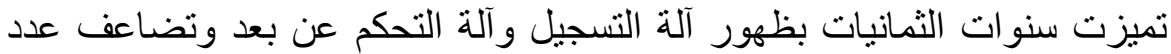

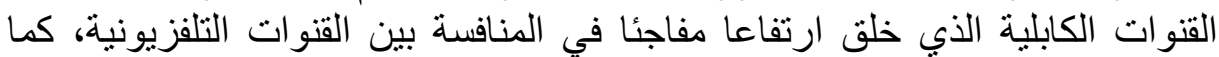

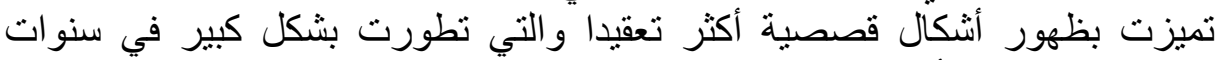
التسعينات وبداية الألفية الثانية.

لقد جعل الدخول في العصر الرقمي مشاهدة التلفزيون خبرة فردية تكيفت معها

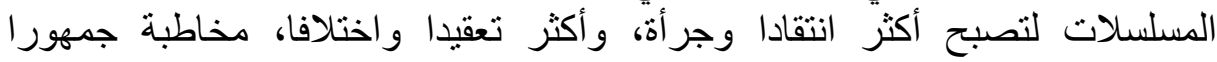
يتناقص شيئا فتشيئا، وهو ما مكنها من الحصول على اعتر اف من النقاد و المتقفين على أنى

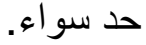

وقد تمحورت للإشكالية الرئيسية لهذه الدراسة حول هذا السؤال الرئيسي: ما هي أهم المحطات التاريخية التي مر بها المسلسل التلفزيوني في الولايات

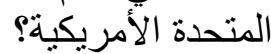
وقد تفر عت عن هذا السؤال مجموعة من الأسئلة الفرعية كالتالي:

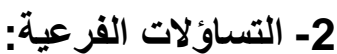
- ما هي أبرز المراحل التي مر بها المسلسل التلفزيوني في الولايات المتحدة

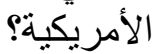

- - ما هي أهم أنو اع المسلسلات التي ظهرت خلال الفترة التي شملتها الدر اسة؟ - ما هي أهم العوامل التي ساعدت على تطور المسلسلات الأمريكية؟

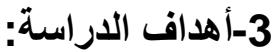

- الوقوف على أهم الهحطات التاريخية التي مر بها المسلسل التلفزيوني في الو لايات المتحدة الأمريكية.

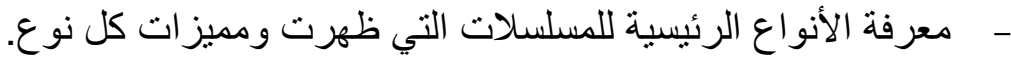
- معرفة أهم العوامل التي ساعدت على تطور المسلسلات الأمريكية خلال الفترة

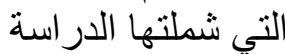

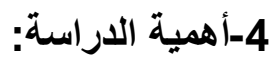

تتلخص أهمية هذه الدراسة في كونها تسلط الضوء على على واحد من أهم الأشكال

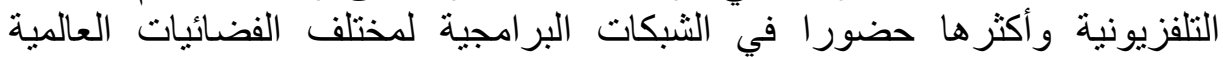

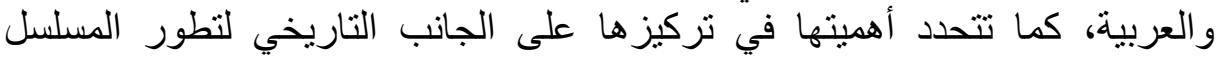
التلفزيوني الذي لم يحظى باهنمام كبير من الباحثين الجامعيين في الجز ائر .

\section{5-تحديد مفاهيم الدراسة:}

المسلسل التلفزيوني: يمكن أن نعتبر المسلسل التلفزيوني كما ير اه الكاتب السوري

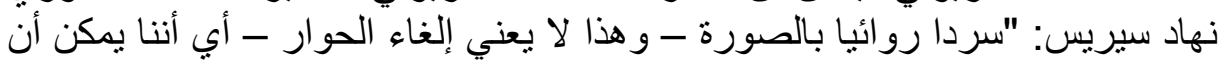

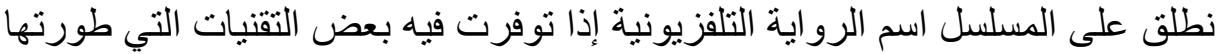


الرواية الأدبية مثل الاهتمام بالعالم الداخلي للشخصيات و إظهار ميولها وضعفها وقلقها وحالاتها النفسية وغير ها "(1) والابنة

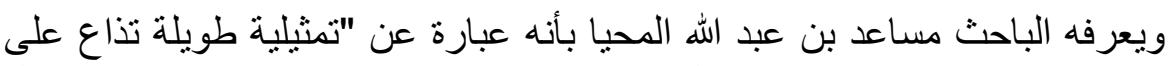

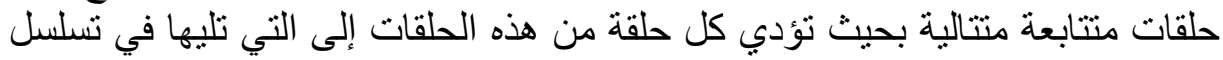

ومنطقية" (2).

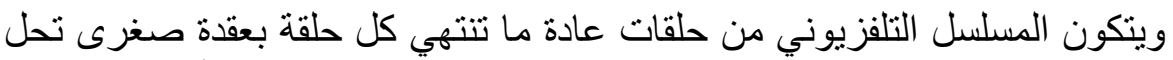

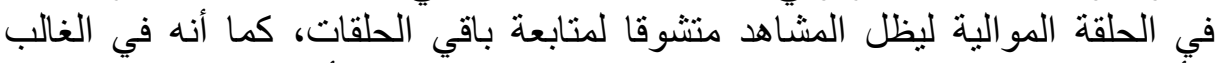
الأعم تكون لمجموع الحلقات عقدة كبرى ينم حلها في الحلقة الأخيرة.

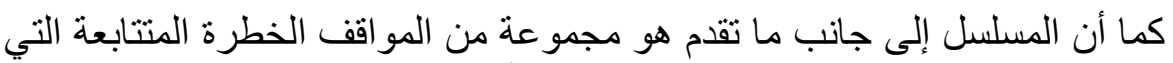

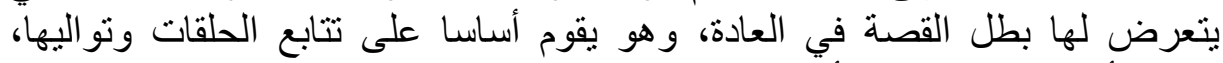

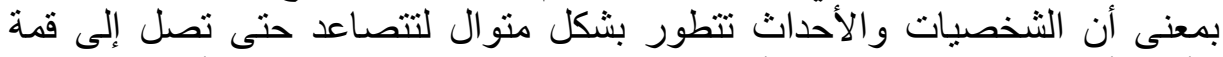

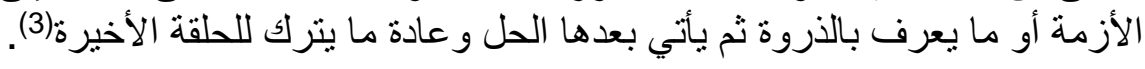

\section{. II}

منهج الدراسة:

تم اعتماد المنهج التاريخي السردي في هذه الدراسة لأنه أكثر المناهج ملائمة

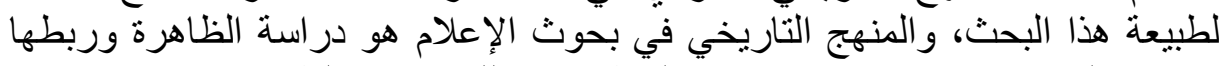

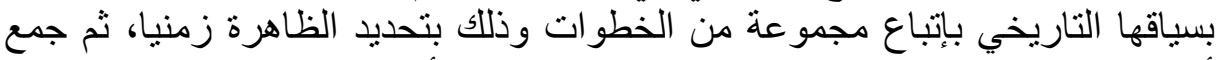

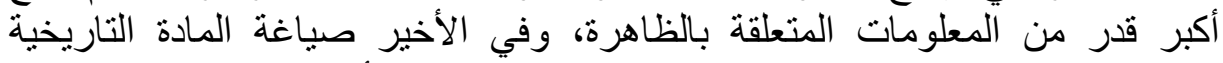

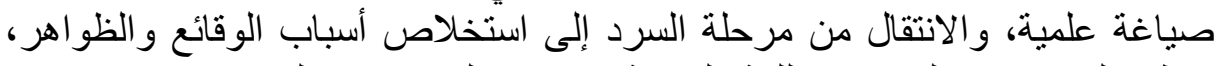

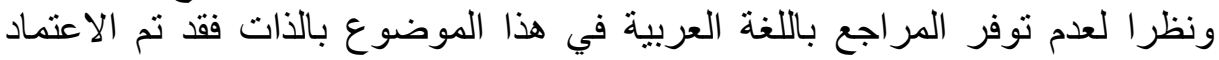

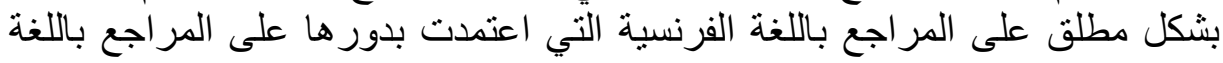
الانجليزية.

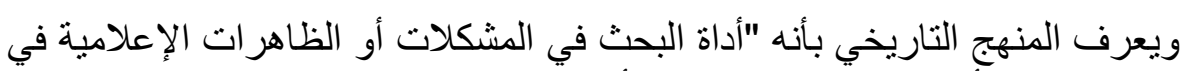

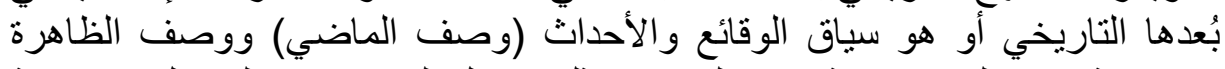

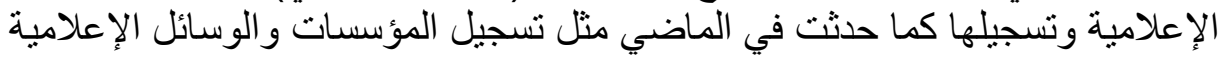
و البارزين فيها" (4)

\section{I التطور التاريخي لأشكال المسلسل التلفزيوني:}

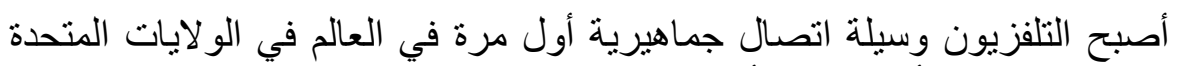

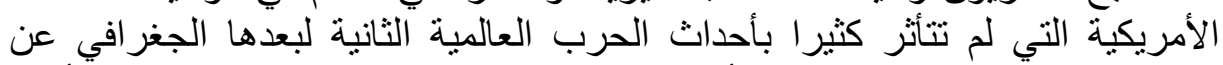

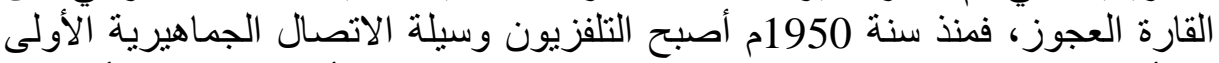

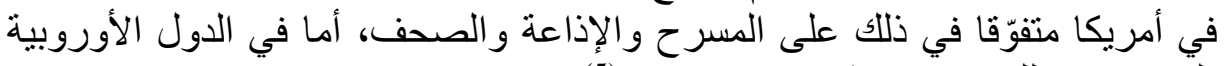

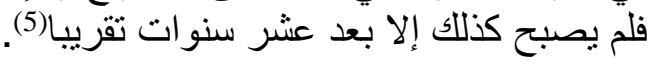

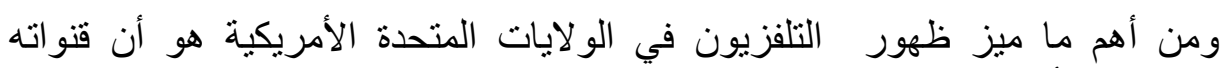

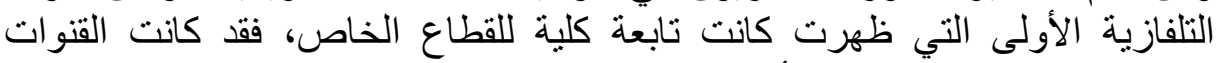

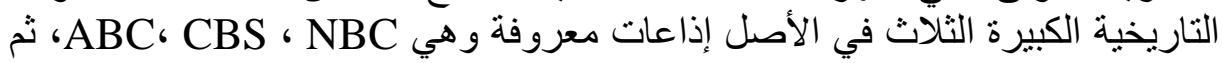

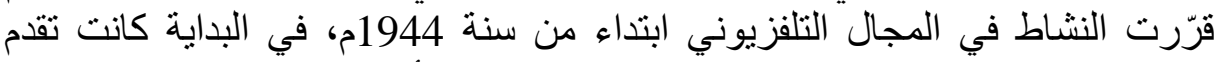

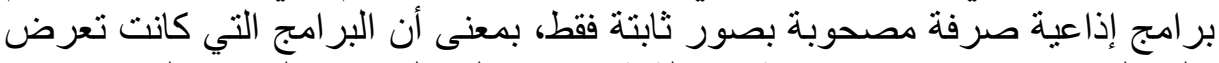

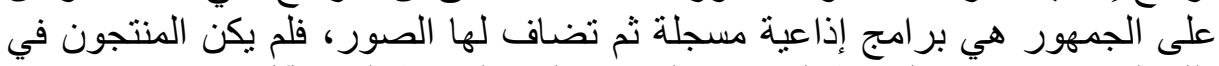
ذلك الوقت يعرفون بالضبط المحتوى المناسب لهذا لهذا الوسيط الجديد(6). 
وبداية من سنة 1946م بدأت قناة NBC بتقديم برامج خاصة لمشاهديها تتمثل في في

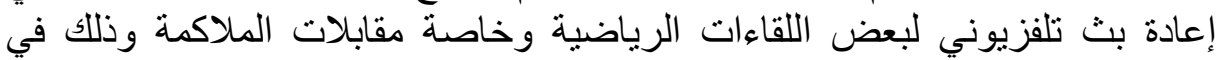

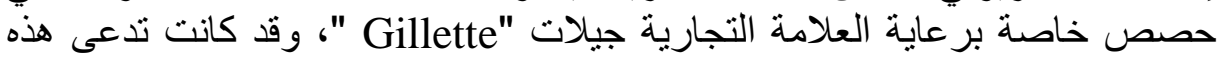
الحصة The Gillette cavalcade of sports، كما كانت تعرض كل أمسية أحد

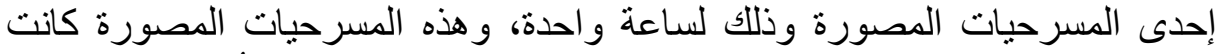

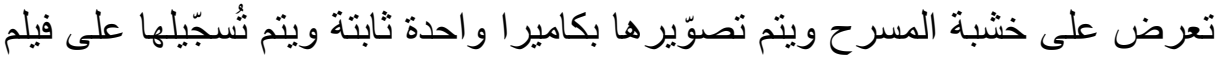
خاص لتعرض بعد ذللك على التلفزيون.

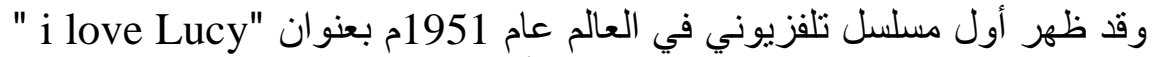

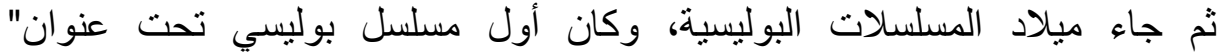
Dragnet

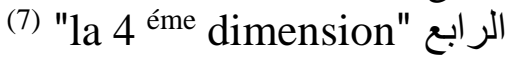

ويمكن أن نميز عدة مراحل مهمة في التطور المتلاحق لأشكال المسلسل التلفزيوني من حيث الثكل، ومن حيث المضمون أيضا، ويمكن تلخيص هذه المحطات المهمة فيما يلي: مين

1.3. المرحلة الأولى: 1950- 1960:

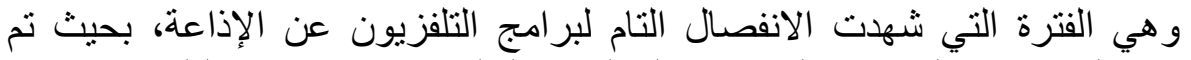

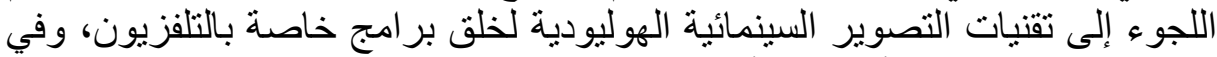

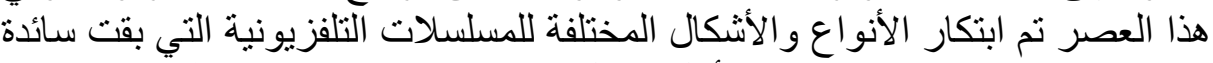

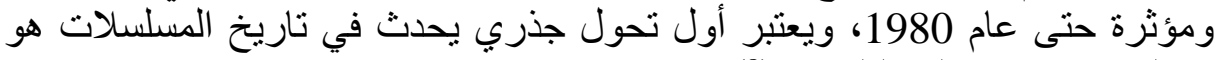

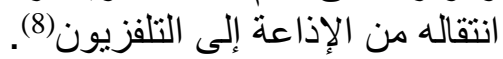

وون أهم الأشكال التي ظهر بها المسلسل التلفزيوني في هذه المرحلة نذكر ما يلي:

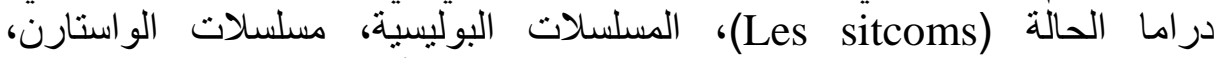
مسلسلات الخيال العلمي، وفيما يلي ملخص مركز لهذه الأنواع(9):

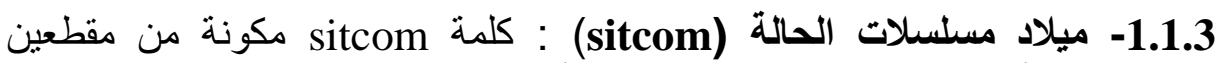

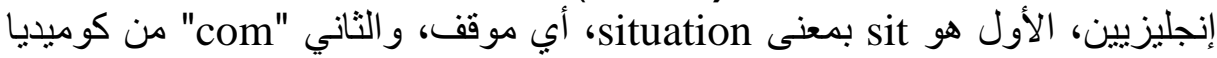

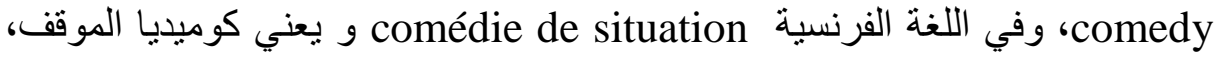
و هو مسمى يطلق على نوع من المسلسلات الكوميدية التي تحمل خصائص تميزها

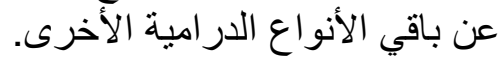

وقد بدأت في الولايات المتحدة بالمسلسل الثهير "أحب لوسي" (I Love Lucy)؛

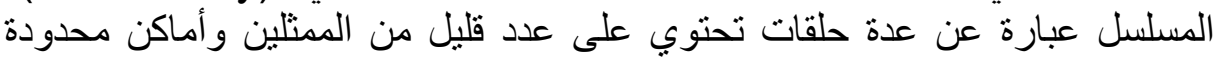

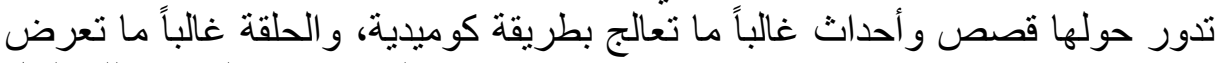

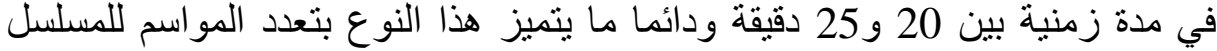
الواحد فكلما زاد عدد المواسم دل ذللك على نجاح المسلسل(10).

ودائما ما يتم تصوير هذه المسلسلات في موقع تصوير داخلي حيث يقوم الممثلون

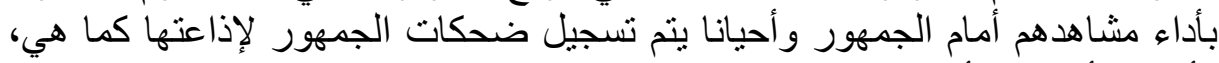

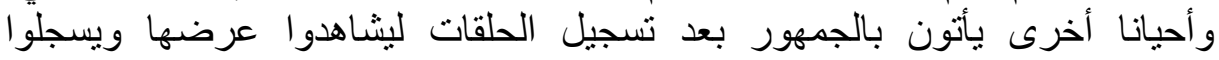
ضحكهم الطبيعي ليتم دمجه ونركيبه باليه مع الصورة لاحقا.

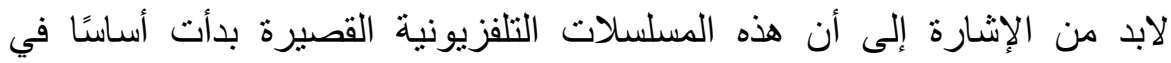

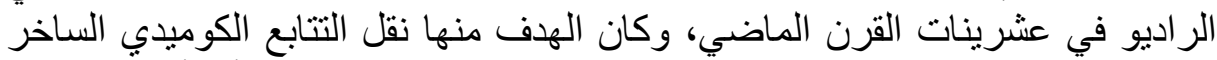

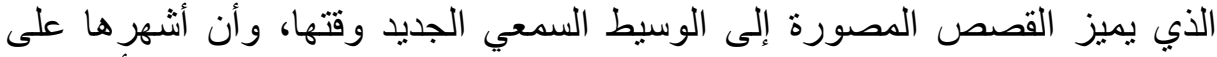
الإطلاق والذي يحمل اسم "Amos and Andy" يقوم ببطولته الثنان من الأمريكيين 
الأفارقة قد ظل يبث عبر الراديو لأكثر من ثلاثين عامًا، قبل أن ينتقل إلى التلفزيون،

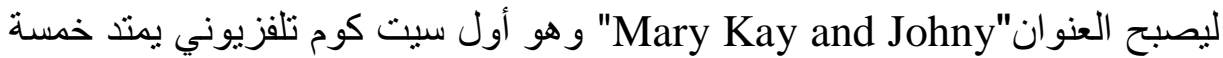

عشر دقيقة.

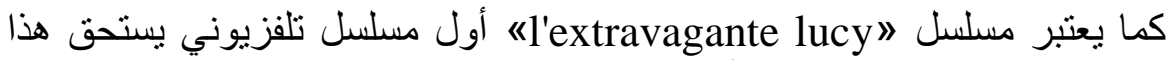

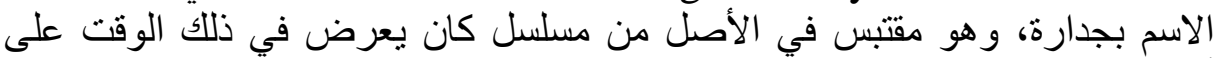

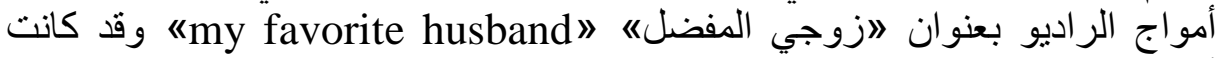

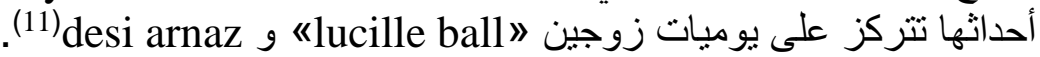

لقد تم إنتاج هذا المسلسل من طرف شركة خاصة تديرها بطلة القصة وهما

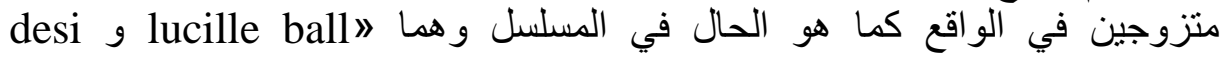
Arnaz

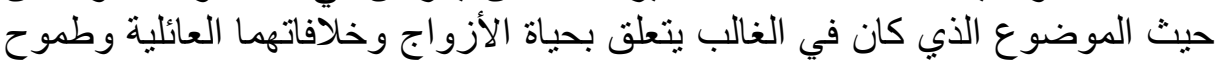

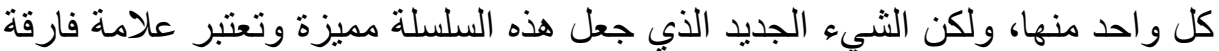

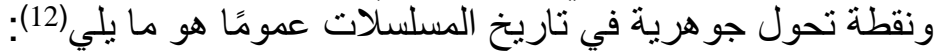

أولا: تمكنت المخرجة من إقناع إدارة CBSبتصوير أحداث المسلسل في هوليود بدهيلا من نيويورك، وهذا للاستفادة من التقنيات الكبيرة التهات التي توجد في في الأستوديو هات السينمائية الهوليودية.

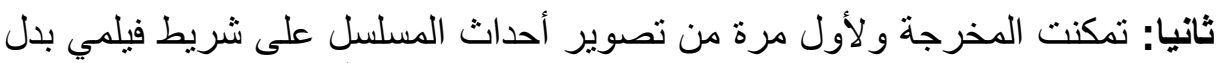

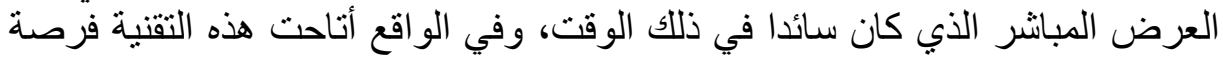

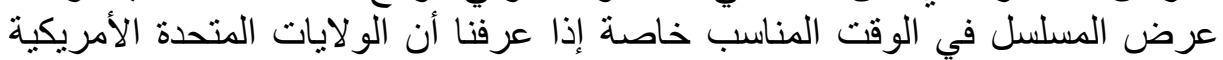

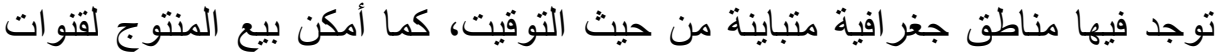

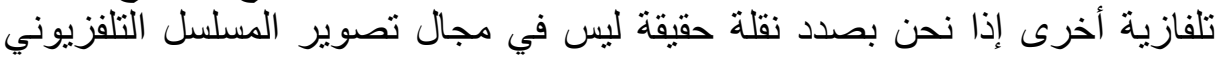
و التقنيات المستعملة لذلك فحسب بل نقلة تسويقية اقتصادية لافتة.

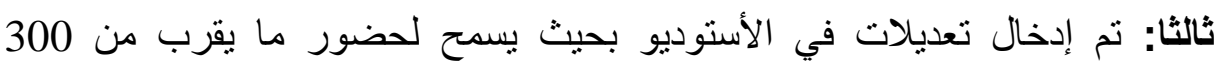

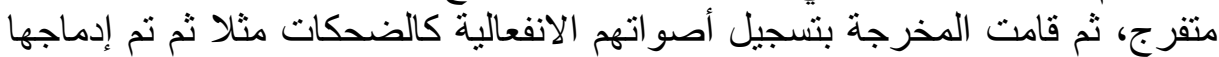

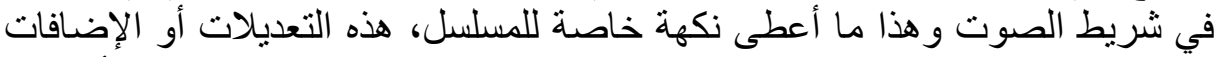

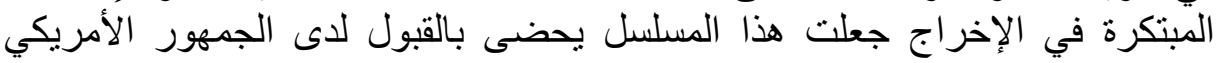

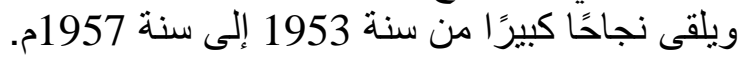

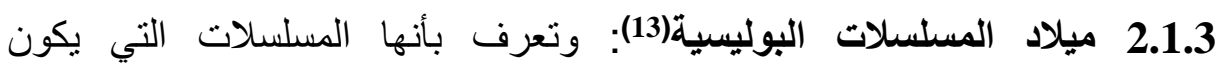

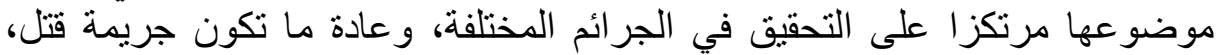

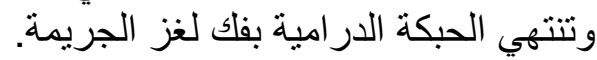

يعتبر مسلسل dragnet أول مسلسل بوليسي بالأبيض والأسود في العالم من 266 حلقة تدوم الحلقة الواحدة 26 دقيقة، و استمر من سنة

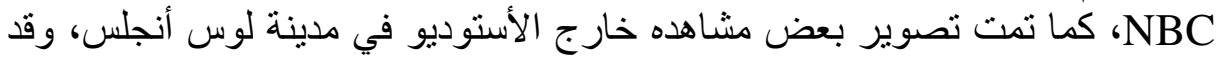

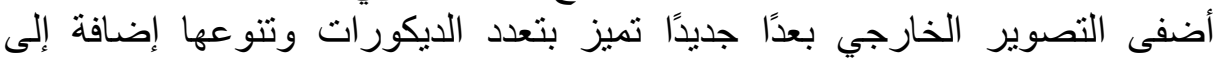

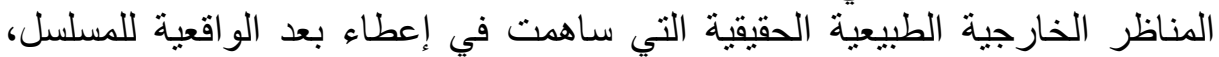

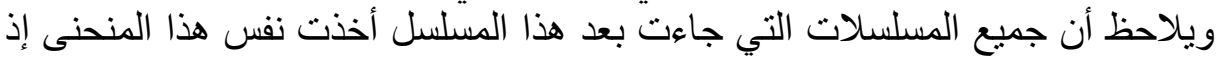

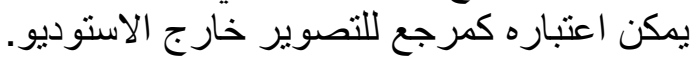
3.1 .3

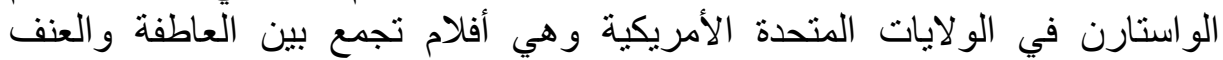
و المغامرة، وتدور أحداثها في الغرب الأمنات الأريكي المنوحش. 
ومع نجاح هذا النوع من الأفلام في السينما بدأت أستديوهات هوليود العملاقة في إنتاج

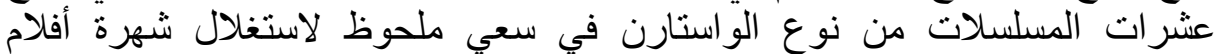

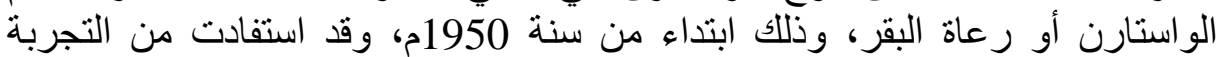

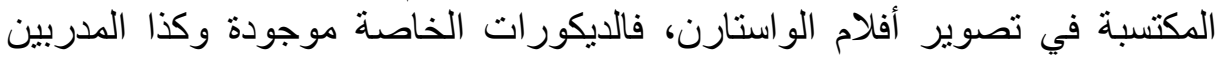
les على ركوب الخيل وحمل السلاح والقيام ببعض الحركات والمشاهد الخطيرة

.cascadeurs

و هكذا منذ سنة 1949م ظهر على الثاشة الصغيرة بطلان مشهور ان في سلسلتين

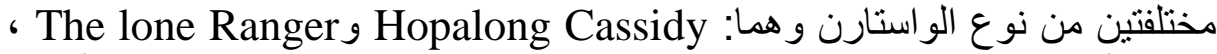
ويذكر أن الممثلين سبق وان شنار الونان في مسلسلات واستارن كانت تذاع على أمواج

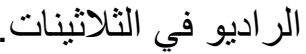

ولعل من أبرز علامات نجاح هذا النوع من المسلسلات هو تمكنها من حصد 150

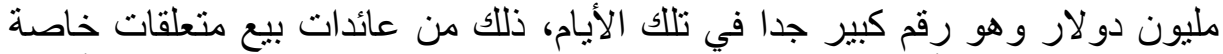

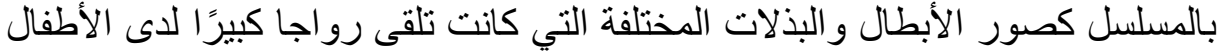

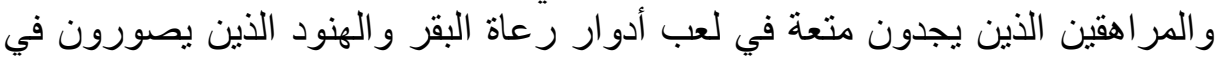

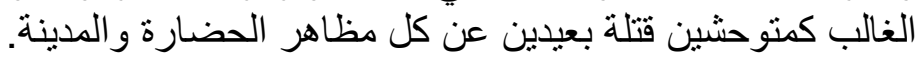
و هذا ما يبين مرة أخرى قدرة المسلسلات التلفزيونية عمومًا في النتأثير على قيطي

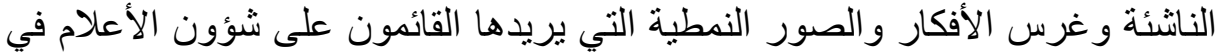
هذا البلد أو ذلك.

ونذكر هنا أن مسلسل" Gunsmoke" يعتبر أطول المسلسلات التلفزيونية في

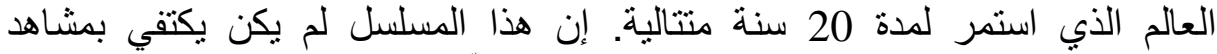

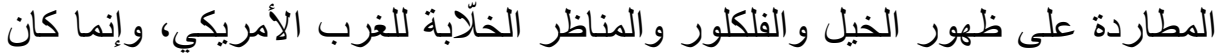

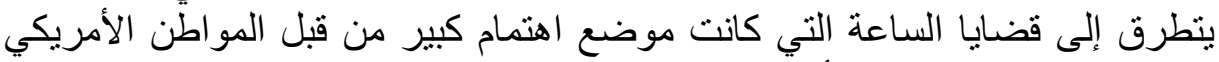

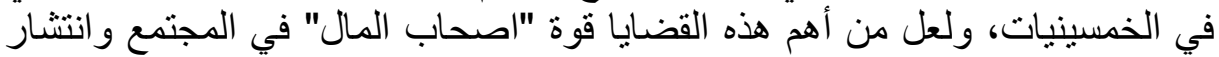

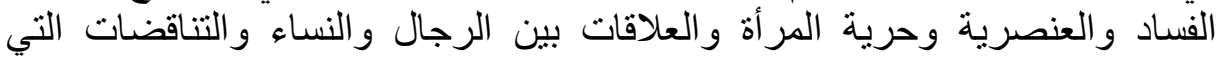

$$
\text { جاءت مع الازدهار و التقدم التكنولو لوجي المتنامي. }
$$

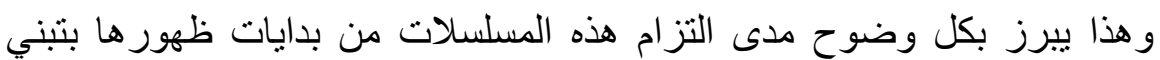

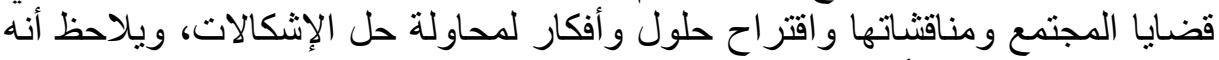

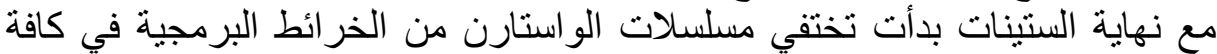

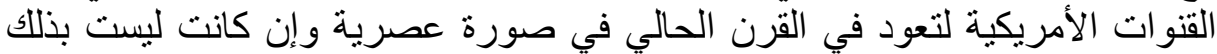

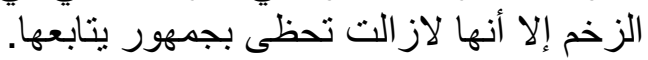

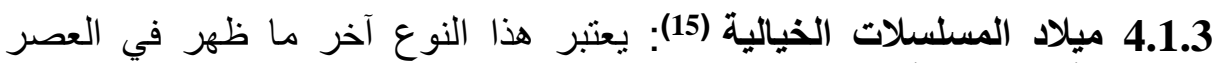

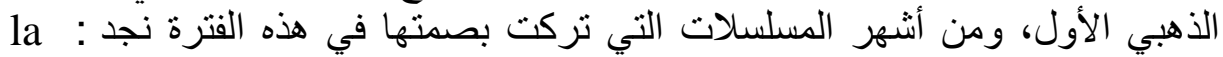
quatrième dimension

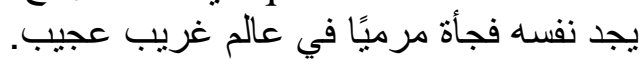

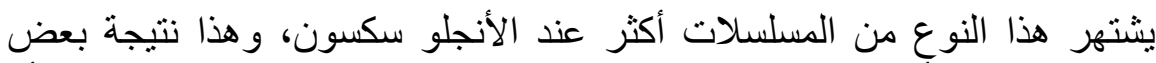

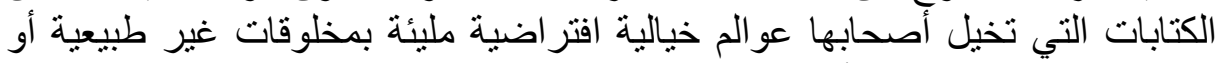

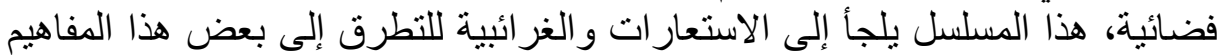

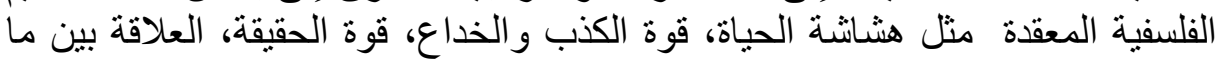

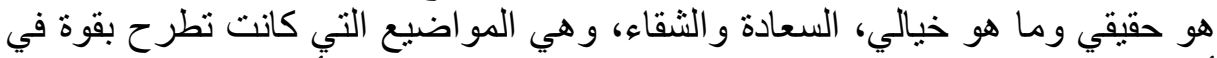

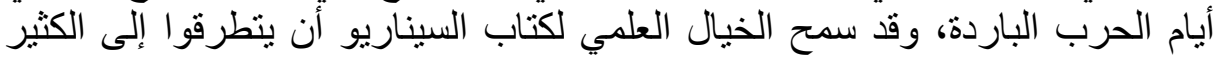

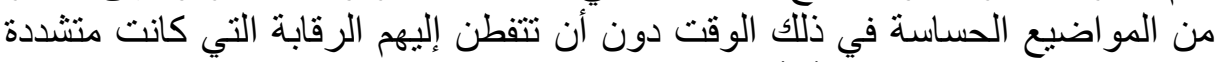

خاصة ضد التيع التيار اليساري. 


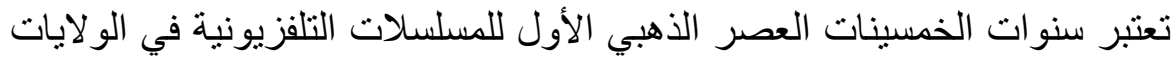

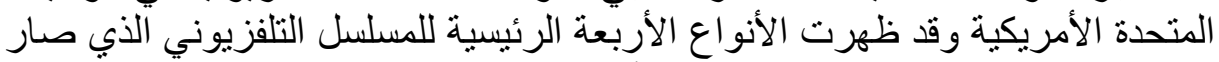

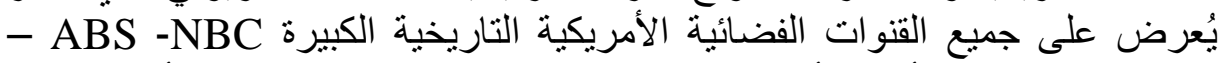

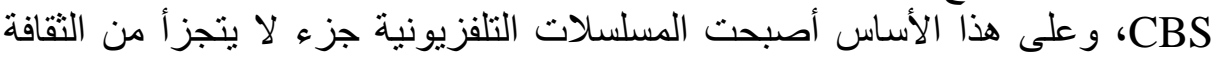

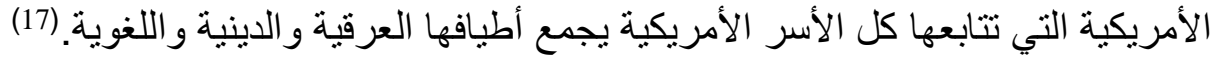

2.3 المرحلة الثاتية: 1980-1960: (18)

في هذه السنوات لم تظهر أشكال كثيرة وجديدة ولكن شهدت تتوعًا وثراء في الإني

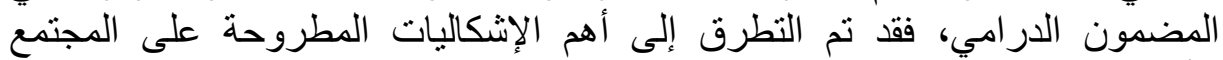

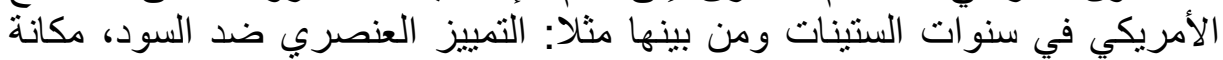

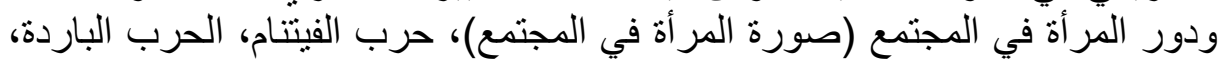
ولعل أهم ما يميّز هذا العصر هو أمو ميلاد المسلسلات الطبية.

1.2 .3 ميلاد المسلسلات الطبية (19):

يلاحظ أن معظم كتاب السيناريو في هذه الفترة كان هدفهم بالأساس هو تثقيف

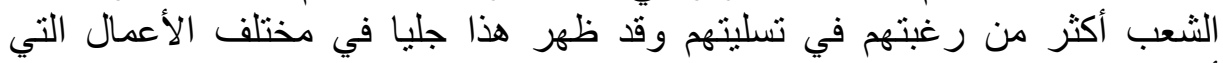

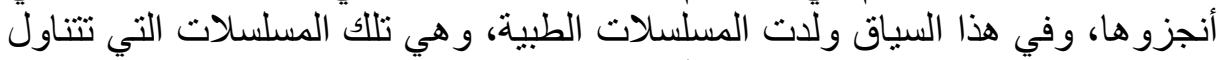

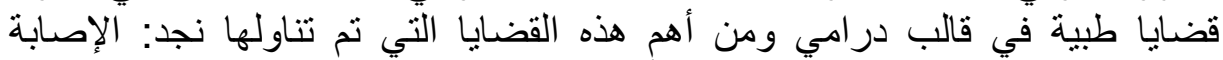

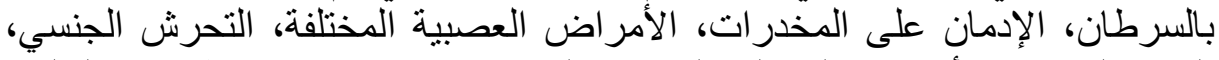

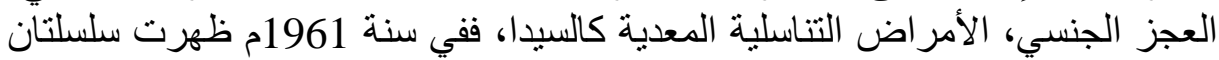

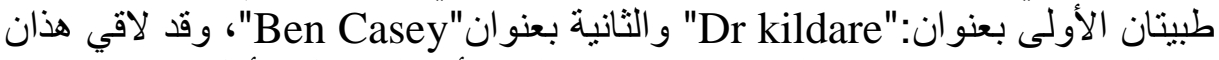

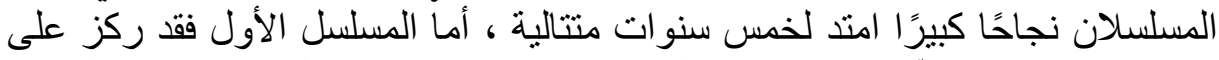

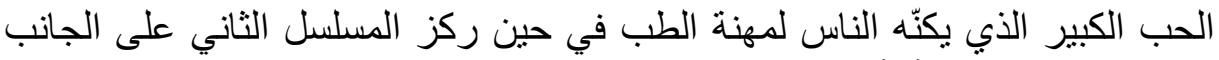
العلمي الثقافي للمهنة(20).

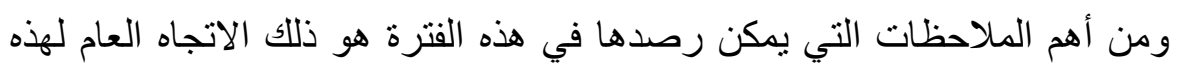

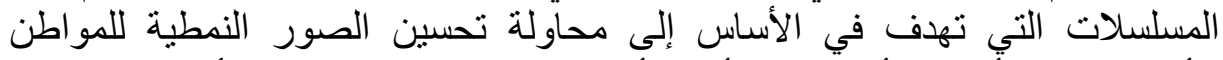

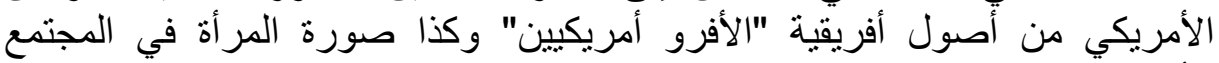

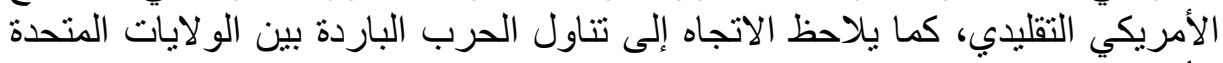

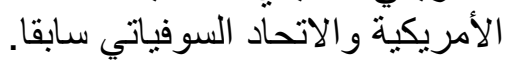

3.3/المرحلة الثالثة 1980- 1990 1921):

يغير التلفزيون وجهه في سنوات الثمانينات وذللك بسبب اختراع جهاز تسجيل

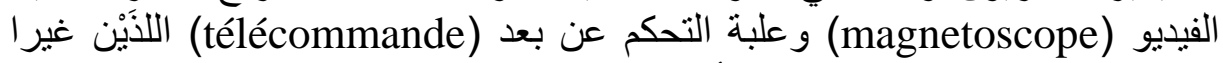

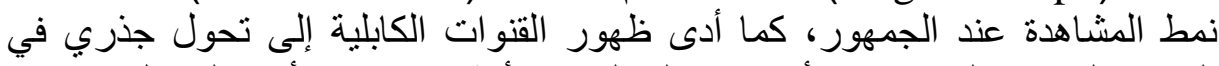

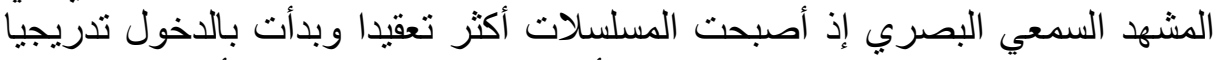

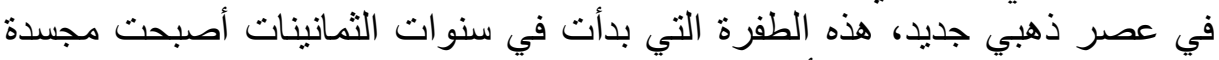

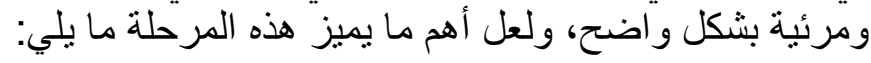

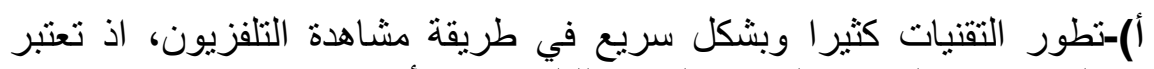

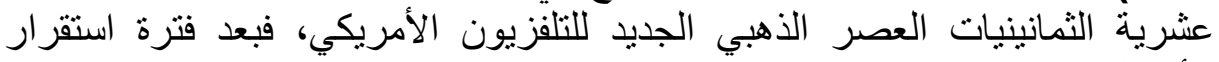

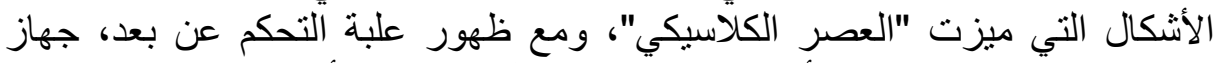

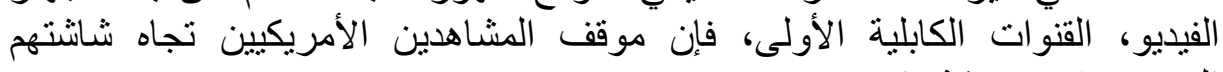
الصغيرة قد تغير كثير ا. الفئ.

بدأ هذا عصر من خلال القدرة على تغيير القنوات(zapping)، والتي ازداد عددها 


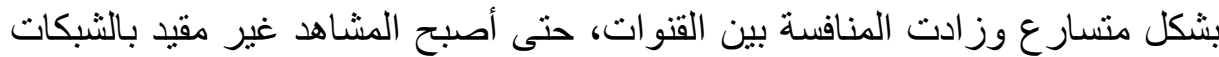

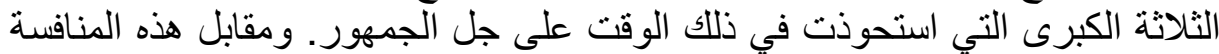

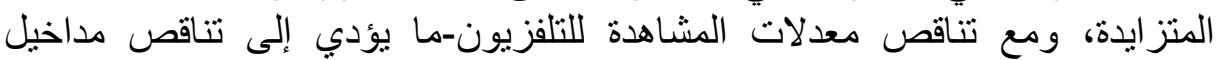

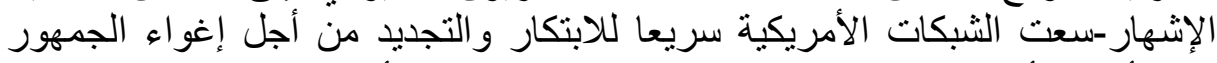

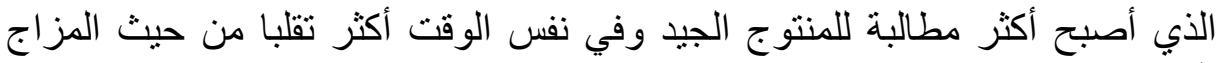

ب)- الابتكار على مستوى الثكل: إن الثورة الأولى في كتابة القصص المتلفزة

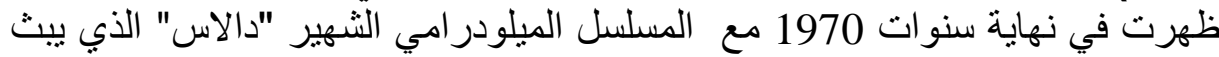
في وقت الذروة، هذا المسلسل في الواقع هو المسلسل الأسبو عي الأول المشكل ابتداء

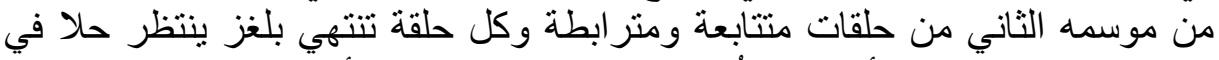

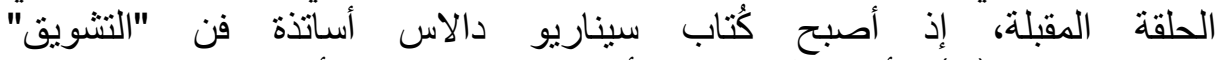
(22) (cliffhanger) ، أي جعل النشويق أثناء الوقت الحاسم للأحداث في نهاية الحلقة

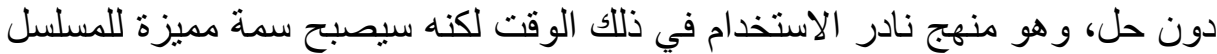

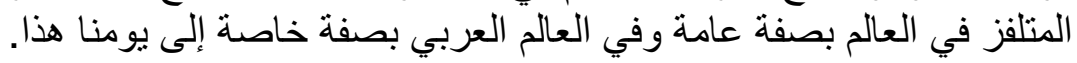

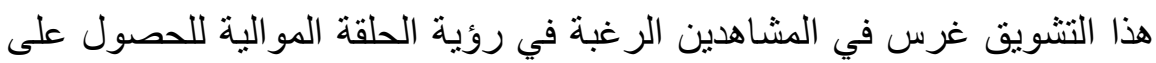

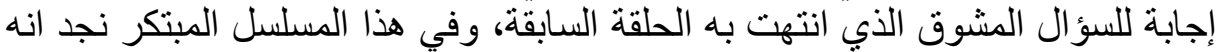

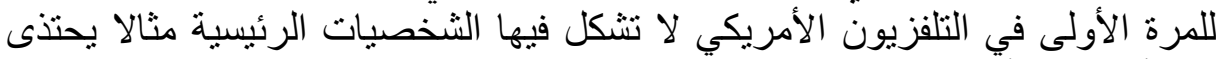
به الأمر الذي أسس لاتجاه سيظهر وسيتضخم إلى يومنا هذا.

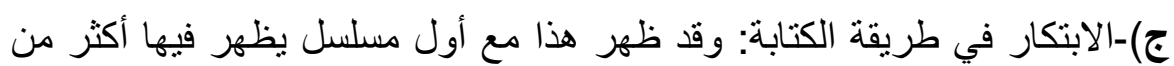

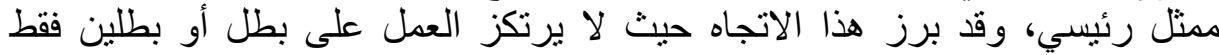

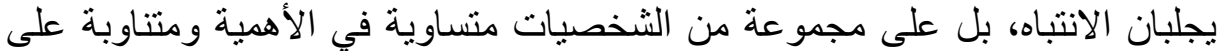
الوقائع المنظورة.

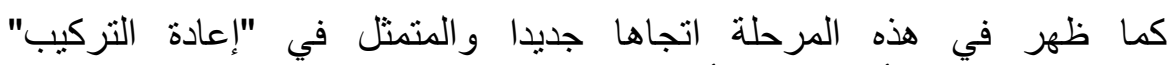

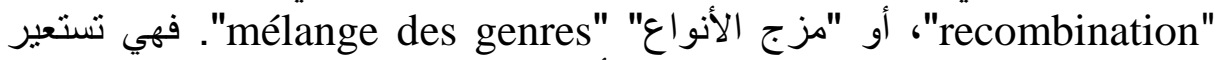

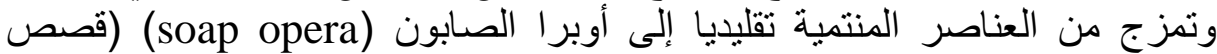

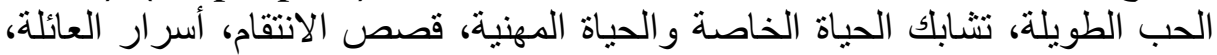

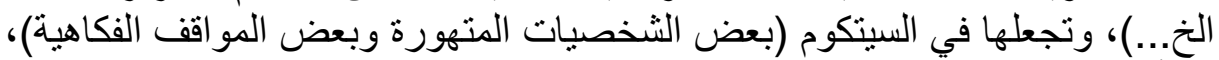
لقد أصبح من الصعب جدا تصنيف مسلسل في نوع واحد. (23) وأحد الأسباب الرئيسية التي تفسر أن المسلسلات أصبحت أكثر إبداعا هو

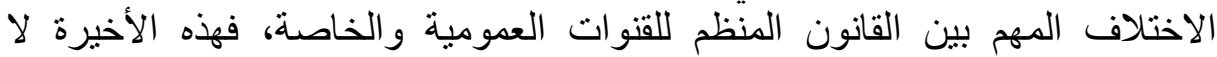

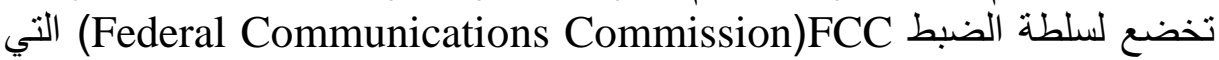

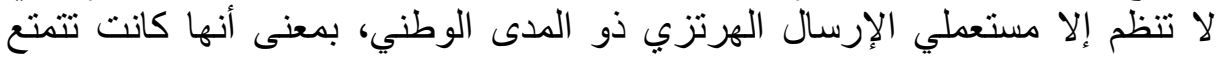

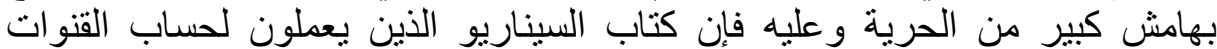
الكابلية يتمتعون بحرية أكبر في الكتابة(24).

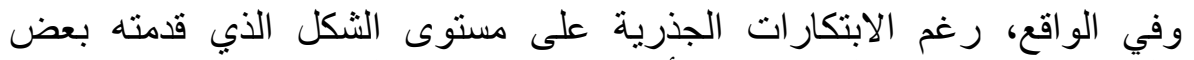

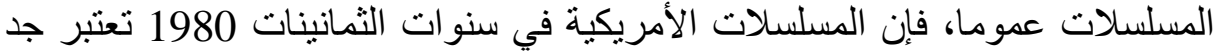

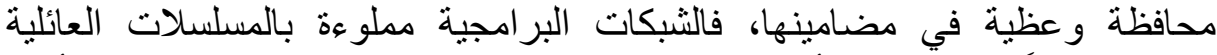

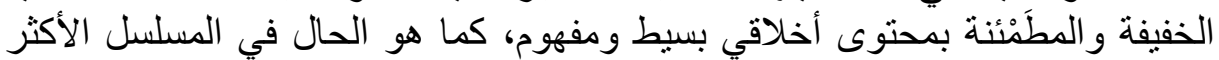

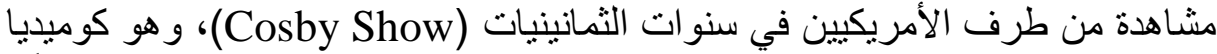
تقدم عائلة من السود أين يعيش الجميع بسعادة، فالمشاكل وحماقات الأطفال تعالَّ

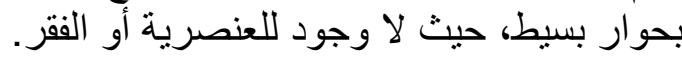
إن مسلسلات سنوات الثمانينيات تظهر إذن كالنقيض تماما لمثيلاتها في الستينيات 
وبداية السبعينيات، غالبا إبداعية على مستوى الثكل، لكن جد محافظة وذات مضدون متكرر.

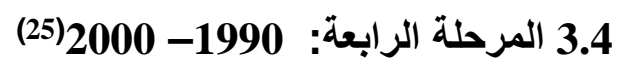

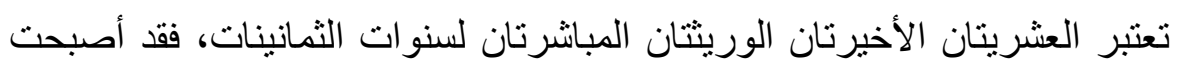

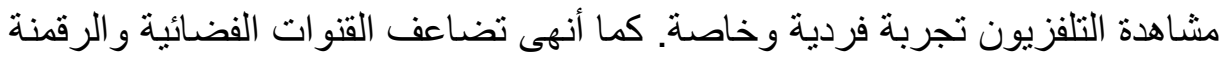

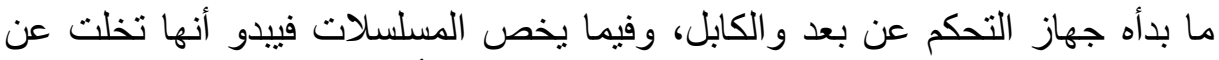

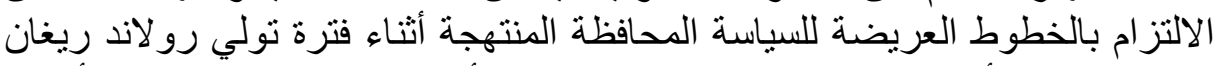

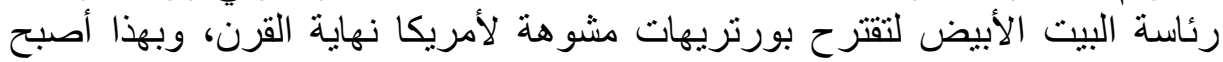

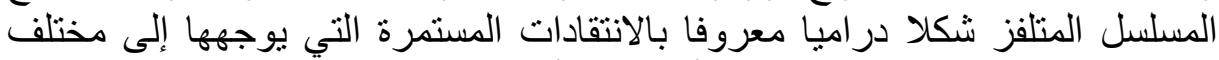

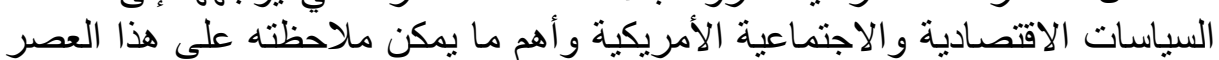
ما بلي (26):

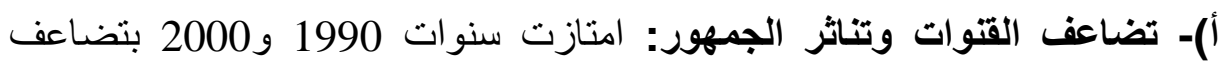

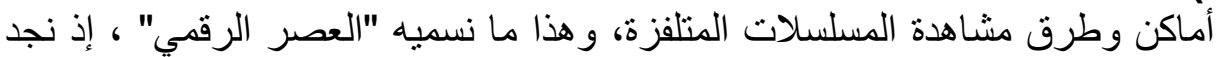

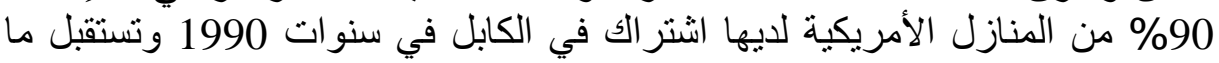

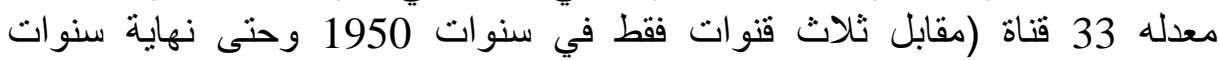

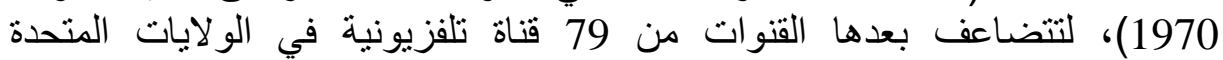

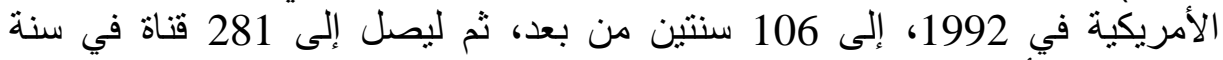

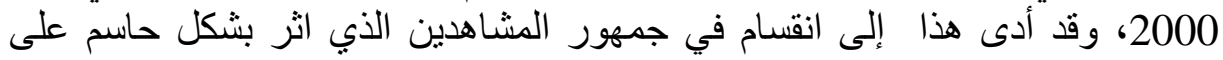

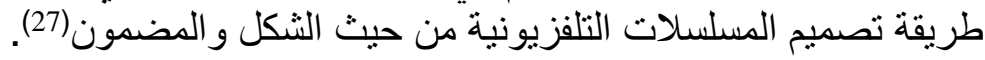

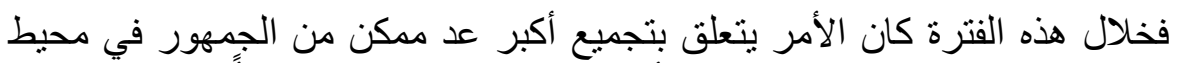

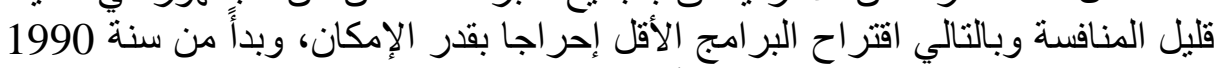

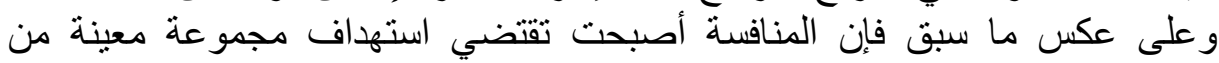
المشاهدين ومنحهم بر امجهم المفضلة.

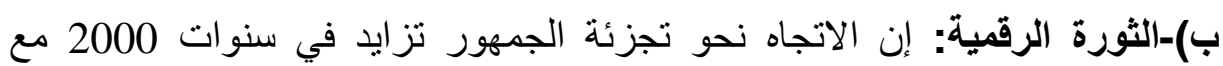

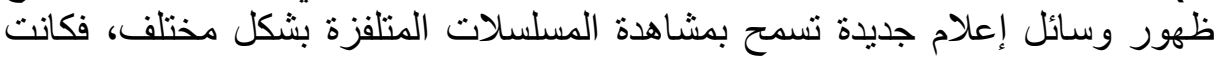

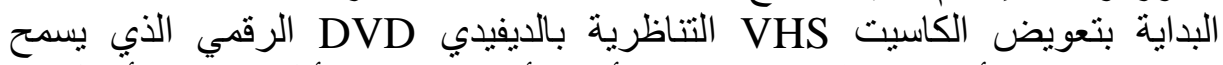

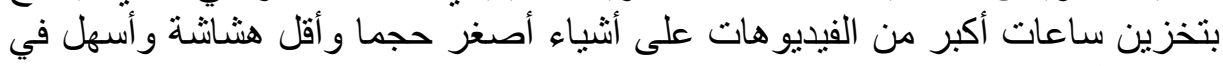
الاستعمال.

في بداية الألفية الثالثة، عُممت آلات التسجيل الرقمية في الولايات المتحدة حيث الاثل

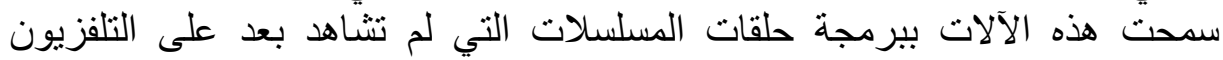

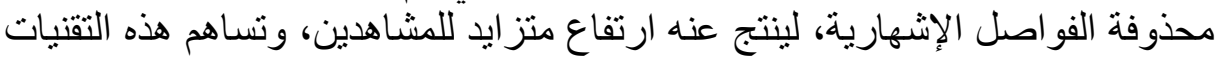

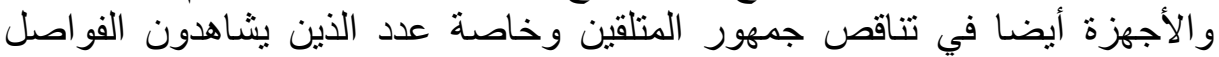
الاشهارية.

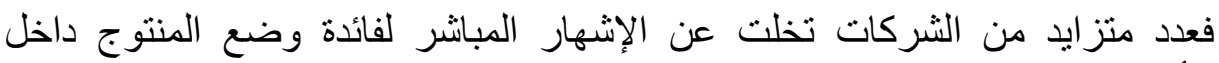

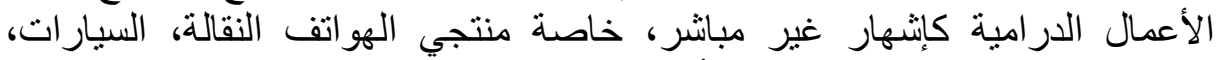

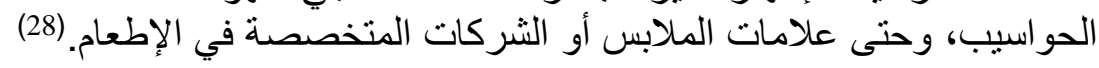
في النصف الثاني من سنوات 2000، تم تعميم الانترنيت ذات التدفق العالي الذي التي التي

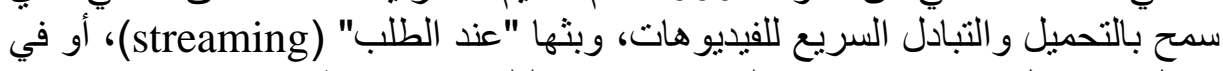

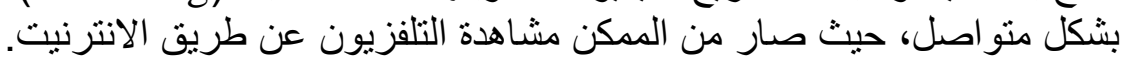

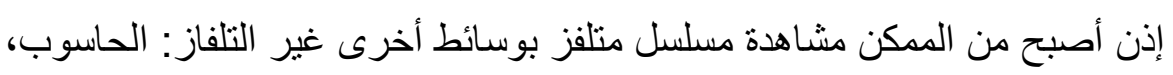


الهاتف النقال، اللوحات الرقمية لكن في الوقت نفسه شهدت شاثـات التلفاز تطورا

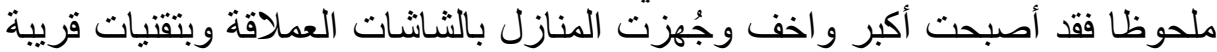

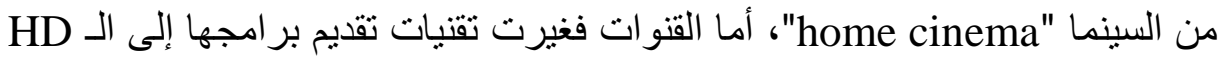

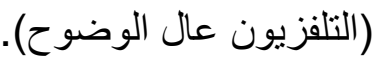

هذا التقدم في الوسائط غير طريقة مشاهدة المسلسلات المتلفزة وشكل تحديا حقيقيا للنموذج الاقتصادي التقليدي المبني على التسعيرة الاشهارية المعتمدة على معيار الجمهور.

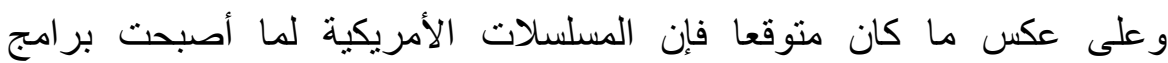

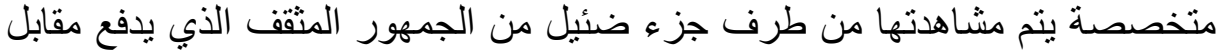

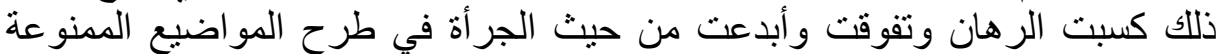

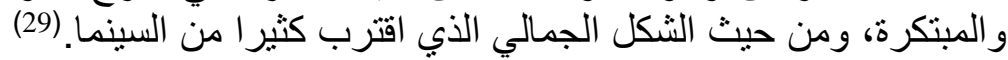

ج)-بورتريه أكثر دقة على المجتمع الأمريكي(30): إذا كانت المسلسلات الأمريكية

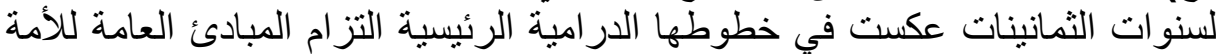

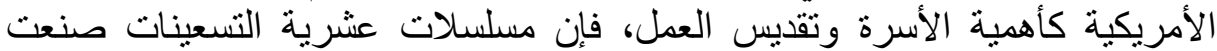

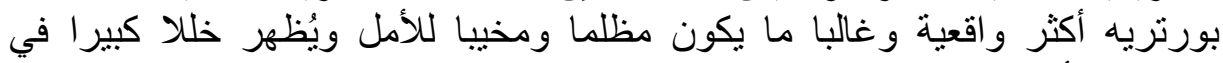
المجتمع الأمريكي.

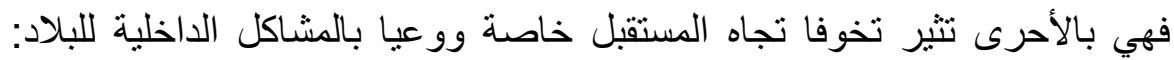
الققر ، البطالة، الجريمة، انحلال العائلة و الروابط الاجتماعية و غيرها، كل هذه الشكوك

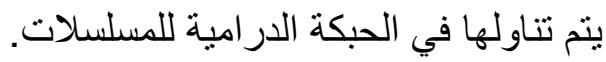

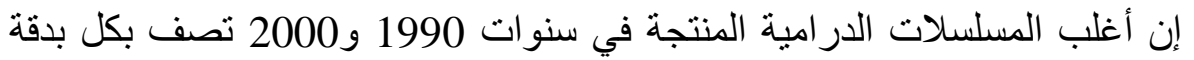
وواقعية تعقد وتتوع المجتمع الامريكي، وهي بالتأكيد فترة المسلسلات الكوميدية

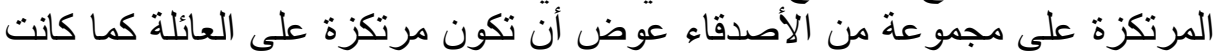

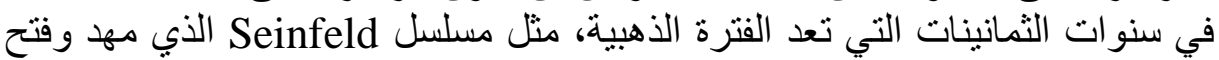

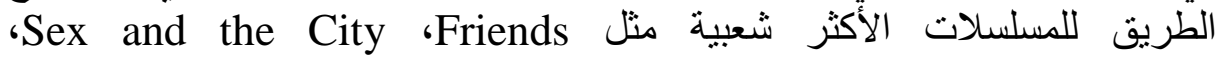
هذه (The Big Bang Theory ،How I Met your Mother ،Entourage المسلسلات تعكس تساؤلات جيل في عالم يلف فيه الثك المبادئ التقليدية (العائلة

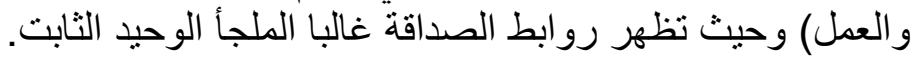

د)-على مستوى الثكل: فإن المسلسلات الكوميدية في سنوات 2000 بدأت تبتعد شيئا

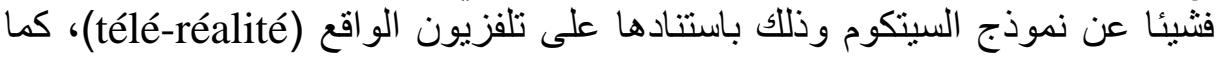

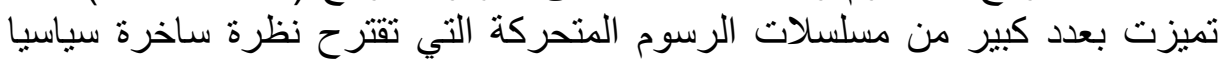

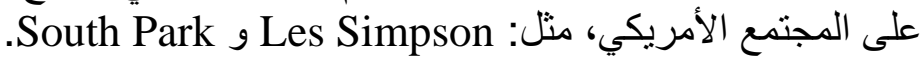

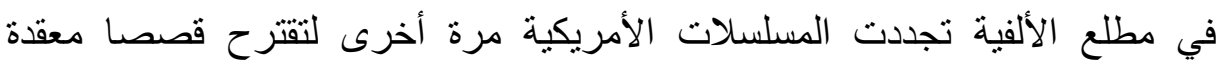
بطريقة غير مسبوقة على جمهور ماز ال يطلب المزيد، هذه المسلسلات استفادت من فن فئرة

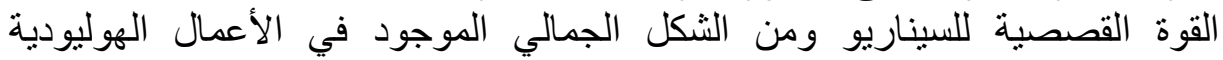
الضخمة وقد جلبت نحو التلفزيون جمهور الفئون مثنقا جديدا عاثقا للسينما. تُعد سنوات 2000 دون شك وبتأثير من المسلسلات التي أنتجتها القناة الخاصة

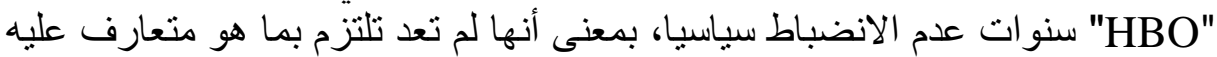

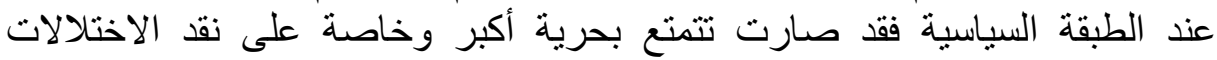
الكبيرة التي ظهرت في مختلف مناحي الحياة.

حيث تشارك المسلسلات في النقاش السياسي إذ أن عددا كبيرا من المسلسلات

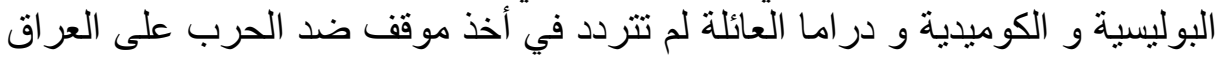




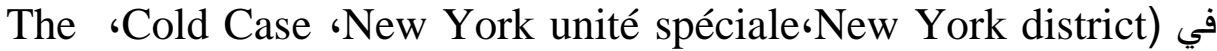
Good Wife )، أو ضد الفساد في جميع المستويات الاجتماعية والاقتصادية في ( 24 (ال)

(The Good Wiffe rheures chrono

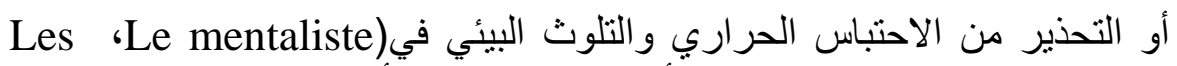
New York district،experts

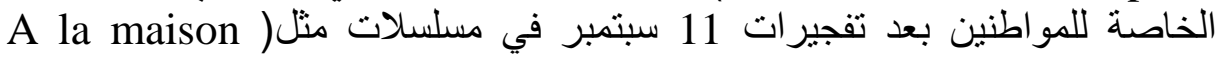

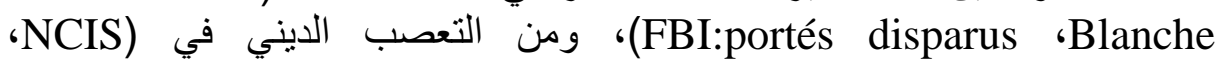
.(Esprits criminels‘Bones

نتائج الدراسة:

1. تطور السلسل التلفزيوني في الولايات المتحدة الأمريكية بشكل كبير، وقد

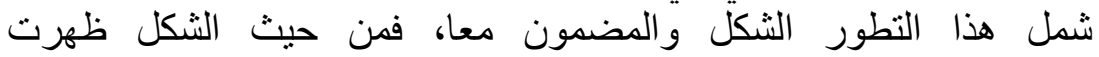

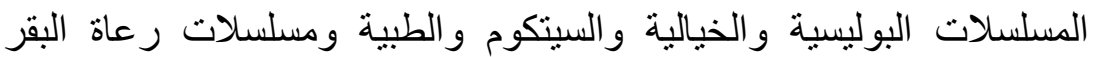
و غير ها، ومن حيث المضمون تطرقت إلى مو اضيع حساسة وشائكة.

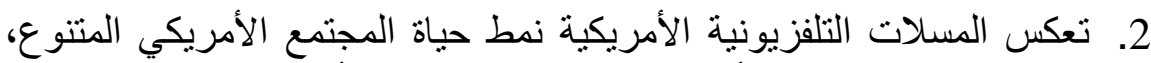
وقد تقترب هذه الصورة أحيانا من الحقيقة وتبتعد في أحيان كثيرة.

3. تحمل المسلسلات الأمريكية مضامين إيديولوجية وقيمية موجها العها إلى الجمهور

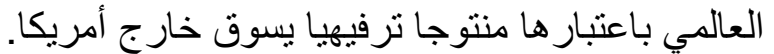

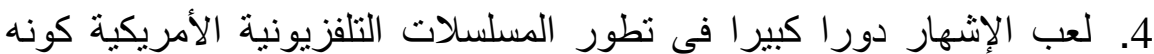
ساهم في الحفاظ على الاستقلال المالي للقنوات الخاصة.

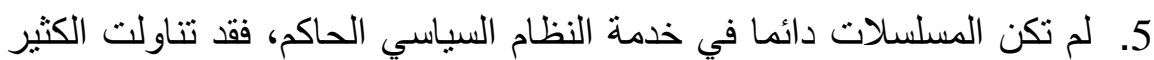

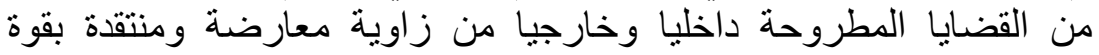

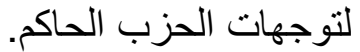

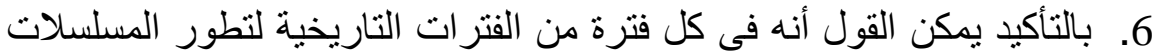

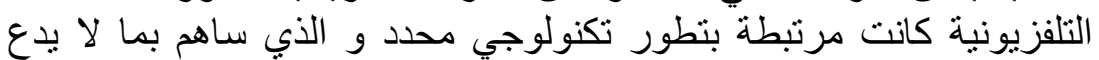

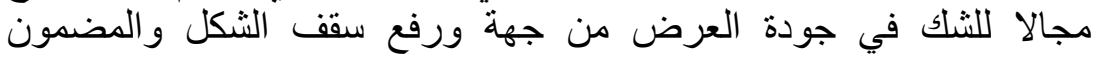

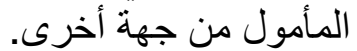

1) - نهاد سيريس، مدخل إلى الرواية التلفزيونية، www.syrigate.com/nihadsyrees/jaridah/mak-005.html ناريخ الولوج:11- 12- 2018

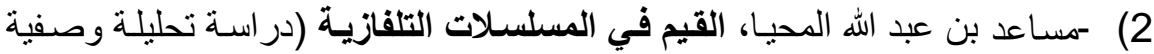
لعينة من المسلسلات التلفازية العربية)، دار العاصمة، الميلة الملكة العربية السعودية،

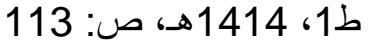

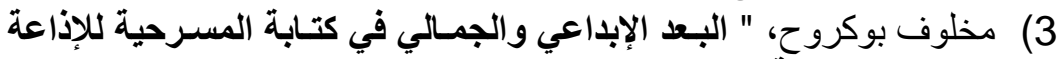

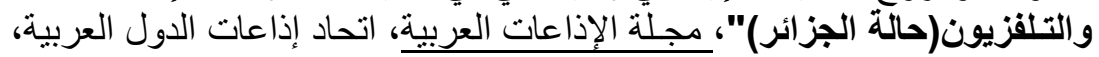

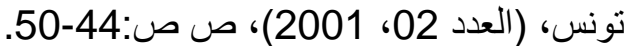
4) محمد عبد الحميد(2000)، البحث العلمي في الاراسات الإعلامية،- القاهرة: عالم الكتب، ص262

5) - David buxton ,(2010). les series televises, forme, idéologie et mode de production ", l'harmattan ,france, 1edition,pp:13-30 
6) -Marjolaine boutet, «soixante ans d'histoires des series televises américaines», revue de recherche en civilization americaine (en ligne),2/2010, mis en ligne le 29 juin 2010, consulté le 4 décembre 2014, URL:http: rrca .Revues.org/248

7) Marjolaine boutet, «soixante ans d'histoires des series televises américaines», revue de recherche en civilization americaine ,en ligne,2/2010, mis en ligne le 29 juin 2010, consulté le 4 décembre 2018 URL:http: rrca .Revues.org/248

8) Marjolaine Boutel, op cit, p:10

9) Allan Gorsën ,(2009) "Séries TV , pourquoi on est tous fans ", Editions Edysseus, france, pp,17-22

10) servine barhes, du " temps de cerveau disponible " ? Rhétorique et semiostylique des séries télévisées dramatiques américaines de prime time diffusées entre 1990 et 2005, pp 15-21

11) -clément combes‘(2013) « la pratique des séries télévisées، une sociologie de l'activité sectorielle» économies and finance, ecole national superieure des mines de paris, p ,15

12) clément combes,(2013) « la pratique des séries télévisées, une sociologie de l'activité spectorielle ». economies and finance, ecole national superieure des mines de paris, p, 16

13) Sarah sepulcher, (2011) " decoder les series televises ", de boek ,France ,1 edition, pp,12-18

14) -Sarah sepulcher، IBID، pp,18-20

15) -Sarah sepulcher، Op.cit , pp,20-21

16) -Nicolas dufour, « les Romans feuilletons du 19ème siècle» pp, 3346

17) -marjolaine boulet، Op ,cit , p ,15

18) -Sarah sepulcher، Op، cit , pp,22-23

19) -Aurélie blot, “ crey's anatomy ou l'art d'être piegé, university Paris » Sorbonne, craat on-line issue $\neq 6$,December 2009, p,34-46

20) -Allan Gorsën , (2009)« Séries TV ,pourquoi on est tous fans », Editions Edysseus, france, $\mathrm{p}, 20$

21) -Marjolaine Boutet, OP.cit

22) -Marjolaine boulet, Op.cit, p, 327

23) -Sarah sepulcher, Op.cit, p,33-34

24) -Mathiew de wasseige , «les séries télé des networks américaines, communication", (en ligne), vol.32.1/2013, mis en ligne le 24-22014, consulté le 30-9-2018, URL : http://communicatio.revues.org/4871;DOI:10;4000/communication.48 71

25) -Allan Gorsën , Series TV, Op.cit, France, pp:29-32

26) -Sarah sepulcher, Op.cit , p:37

27) -Sarah sepulcher, Op.cit , p:38

28) -Sarah sepulcher, Op.cit ,p:39

29) -Sarah sepulcher, IBID, p:42-44 
30) -jean-pierre equenazi, « pouvoir des séries télévisées,

communication» (en ligne), vol 32/2/2013,mis en ligne le 25-22014,consulté le 29-9-2018 mis en ligne le 25-2- 2014,consulté le 29-9-2018 URL :

http://communicatio.revues.org/4931;DOI:10;4000/communicati on.4931 